\title{
Effect of different supplemental irrigation strategies on photosynthetic characteristics and water use efficiency of wheat
}

Jikun $\mathrm{Xu}^{1}$, Zhenwen $\mathrm{Yu}^{1}, \mathrm{Yu} \mathrm{Shi}^{1 *}$, Peiwu Guo ${ }^{1}$, and Yuqiu Wang ${ }^{2}$

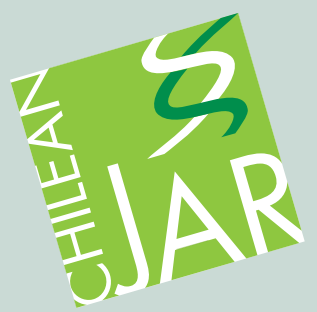

\section{ABSTRACT}

Water resource scarcity has been increasingly becoming a threat to wheat (Triticum aestivum L.) production in North China Plain. Thus, a water-saving irrigation strategy should be urgently developed. We conducted a $2-y r$ field experiment to examine the effects of supplemental irrigation (SI) on the photosynthetic characteristics and water use efficiency (WUE) of wheat. This study employed two SI strategies: A quota SI using $60 \mathrm{~mm}$ water at jointing and anthesis stages (W1) and soil moisture testing SI (W2), which brings the target relative soil water content of 0-40 cm soil layer to $70 \%$ field capacity at jointing and anthesis stages. A non-irrigated treatment (W0) was used as control. Results showed that W2 significantly improved the water uptake in $80-160 \mathrm{~cm}$ soil layer compared with W1. Moreover, flag leaf photosynthetic rate, stomatal conductance, and transpiration 14-28 d after anthesis were highest in W2 successively followed by W1 and W0, and the difference was significant. Dry matter (DM) at maturity, DM accumulation post-anthesis and its contribution ratio to grain were significantly higher in $\mathrm{W} 2$ than in the other treatments. ${ }^{13} \mathrm{CO}_{2}$ labeling results indicated that W2 promoted $\delta^{13} \mathrm{C}$-photosynthate accumulation in grain. In 2012-2013 growing season, the grain yield increased by $56.05 \%$ and $5.74 \%$ and WUE increased by $26.17 \%$ and $6.34 \%$ in W2 compared with those in W0 and W1, respectively. In 2013-2014 growing season, the grain yield increased by $41.82 \%$ and $5.90 \%$ and WUE increased by $28.24 \%$ and $13.03 \%$ in W2 compared with those in W0 and $\mathrm{W} 1$, respectively. Therefore, $\mathrm{W} 2$ is a high-yield and watersaving treatment.

Key words: Dry matter, photosynthesis rate, quota supplemental irrigation, soil moisture testing supplemental irrigation, Triticum aestivum.

${ }^{1}$ Shandong Agricultural University, College of Agronomy, $\mathrm{Nr} 61$, Daizong Street, Tai' an, Shandong Province, 271018, P.R. China.

*Corresponding author (shiyu@sdau.edu.cn).

${ }^{2}$ Yanzhou Meteorological Administration, Nr 100, East Ring Road, Jining, Shandong Province, 272100, P.R. China.

Received: 5 May 2017.

Accepted: 27 August 2017.

doi:10.4067/S0718-58392017000400346

\section{INTRODUCTION}

North China Plain is one of the major food-producing regions in China, producing approximately $50 \%$ of the country's wheat supply (Fan et al., 2016). In this region, the annual precipitation is $550 \mathrm{~mm}, 20 \%-30 \%$ of which is received during the wheat growing season, and this precipitation level can meet only $25 \%$ $40 \%$ of the evaporanspiration (ET) in wheat (Fang et al., 2010). Supplemental irrigation (SI) is needed to ensure high wheat grain yield. However, water resource scarcity caused by excessive exploitation of groundwater has threatened crop production $(\mathrm{Hu}$ et al., 2010). The amount of irrigation needed in traditional SI practices reaches $310 \mathrm{~mm}$, and the water use efficiency (WUE) of these practices is only $13-17 \mathrm{~kg} \mathrm{~mm}^{-1}$ (Sun et al., 2011; Zhang et al., 2011), which is lower than that in most wheat-producing areas worldwide (Zwart and Bastiaanssen, 2004). Therefore, effective water-saving irrigation techniques should be urgently developed.

Quota supplemental irrigation (SI) is a water-saving scheme that reduces irrigation frequency and amount per time. In this scheme, $60-75 \mathrm{~mm}$ irrigation water is used two to three times at key growing stages (jointing, booting, flowering, and milking stages) of wheat (Li et al., 2009; Zhao et al., 2013; Wang et al., 2014a). Quota SI with $60 \mathrm{~mm}$ water per time at jointing and heading stages is commonly employed in North China Plain ( $\mathrm{Li}$ et al., 2009). However, there are some limitations in these studies, as they did not consider the effect of soil water conditions before irrigation on the irrigation amount, water consumption and wheat production. Our previous study by Guo et al. (2015) determined the irrigation amount by measuring the soil moisture at soil depths of 0-20 cm (D20), 0-40 cm (D40), and 0-60 cm (D60) to investigate the response of photosynthetic characteristics of flag leaves to the SI. The results showed that the total irrigation in the D40 treatment were 62.4 and $118.2 \mathrm{~mm}$ in 2011-2012 and 2012-2013 growing seasons, respectively, which were 15.3 and $54.0 \mathrm{~mm}$ higher than D20, but 23.1 and $21.0 \mathrm{~mm}$ lower than D60 in the two growing seasons, respectively. So D40 could be considered as a high yield and water-saving treatment.

Wheat grain yield depends on two mechanisms: Transfer of current assimilates directly into the grain post-anthesis and remobilization of stored assimilates in vegetative organs (Ercoli et al., 2008). The DM accumulates post-anthesis which is produced by photosynthesis of flag leaves and spikes accounts for more than $60 \%$ of grain yield (Fang et al., 2006), indicating a positive correlation between grain yield and DM accumulation post-anthesis (Ye et al., 2011; Meng et al., 2013). Water deficit post-anthesis reduces photosynthesis and DM accumulation, 
resulting in reduced grain weight and grain yield (Plaut et al., 2004; Bahrani et al., 2011). Dong et al. (2013) used $60 \mathrm{~mm}$ water for each round of irrigation and found that DM accumulation post-anthesis and its contribution to the grain of the treatment group that was irrigated twice at the jointing and anthesis stages (W2) are higher by $16.66 \%$ and $16.51 \%$ than those irrigated only once at the jointing stage (W1), respectively. Correspondingly, the grain yield was $7324.4 \mathrm{~kg} \mathrm{ha}^{-1}$, which is $349.7 \mathrm{~kg} \mathrm{ha}^{-1}$ higher than that in W1, and the WUE of W2 was $19.22 \mathrm{~kg} \mathrm{ha}^{-1} \mathrm{~mm}^{-1}$, which is $0.56 \mathrm{~kg} \mathrm{ha}^{-1} \mathrm{~mm}^{-1}$ lower than that in $\mathrm{W} 1$.

In this experiment, soil moisture testing SI and quota SI treatments were used to investigate the effects of SI on the characteristics of flag leaf photosynthesis and DM production, as well as determine the most suitable watersaving and high-yielding irrigation strategy for wheat. The result is expected to serve as a theoretical basis for water management for wheat to facilitate water-efficient and highyield cultivation.

\section{MATERIALS AND METHODS}

\section{Experimental site}

A field experiment was conducted during wheat growing seasons 2012-2013 and 2013-2014 in Shijiawangzi Village, Yanzhou ( $35^{\circ} 42^{\prime} \mathrm{N}, 116^{\circ} 41^{\prime}$ E, $55 \mathrm{~m}$ a.s.1.), Shandong Province, which is located at the center of the North China
Plain. This region presents a warm temperate semi-humid continental climate with an annual average temperature, accumulated sunshine, and precipitation of $13.6^{\circ} \mathrm{C}, 2461$ $\mathrm{h}$, and $621.2 \mathrm{~mm}$, respectively. The groundwater is $25 \mathrm{~m}$ deep. The precipitation during 2012-2013 and 2013-2014 wheat growing seasons was 225 and $156 \mathrm{~mm}$, respectively. The precipitation events during 2012-2013 and 2013-2014 wheat growing seasons are shown in Figure 1.

The soil texture was loam consisting of $29.6 \%$ clay, $37.3 \%$ silt, and $33.1 \%$ sand. Table 1 shows soil nutrients at $0-20 \mathrm{~cm}$ soil layer, and field capacity (FC) and soil bulk at $0-40 \mathrm{~cm}$ soil layers.

Table 1. Soil nutrient of $0-20 \mathrm{~cm}$ soil layer, and field capacity and soil bulk of 0-20 and 20-40 cm soil layers in 2012-2013 and 20132014 growing seasons.

\begin{tabular}{|c|c|c|c|}
\hline \multirow[b]{2}{*}{ Items } & \multirow[b]{2}{*}{ Soil layer } & \multicolumn{2}{|c|}{ Growing season } \\
\hline & & 2012-2013 & 2013-2014 \\
\hline Soil organic matter, $\%$ & $0-20 \mathrm{~cm}$ & 1.47 & 1.43 \\
\hline Total N, \% & & 0.12 & 0.13 \\
\hline Available $\mathrm{N}, \mathrm{mg} \mathrm{kg}^{-1}$ & & 112.69 & 112.67 \\
\hline Available $\mathrm{P}, \mathrm{mg} \mathrm{kg}^{-1}$ & & 35.53 & 38.50 \\
\hline Available $\mathrm{K}, \mathrm{mg} \mathrm{kg}^{-1}$ & & 113.92 & 110.43 \\
\hline Field capacity, \% & & 24.80 & 25.32 \\
\hline Bulk density, $\mathrm{g} \mathrm{cm}^{-3}$ & & 1.57 & 1.59 \\
\hline Field capacity, $\%$ & $20-40 \mathrm{~cm}$ & 21.96 & 23.56 \\
\hline Bulk density, $\mathrm{g} \mathrm{cm}^{-3}$ & & 1.65 & 1.65 \\
\hline
\end{tabular}

Figure 1. Precipitation events during 2012-2013 and 2013-2014 wheat growing seasons.

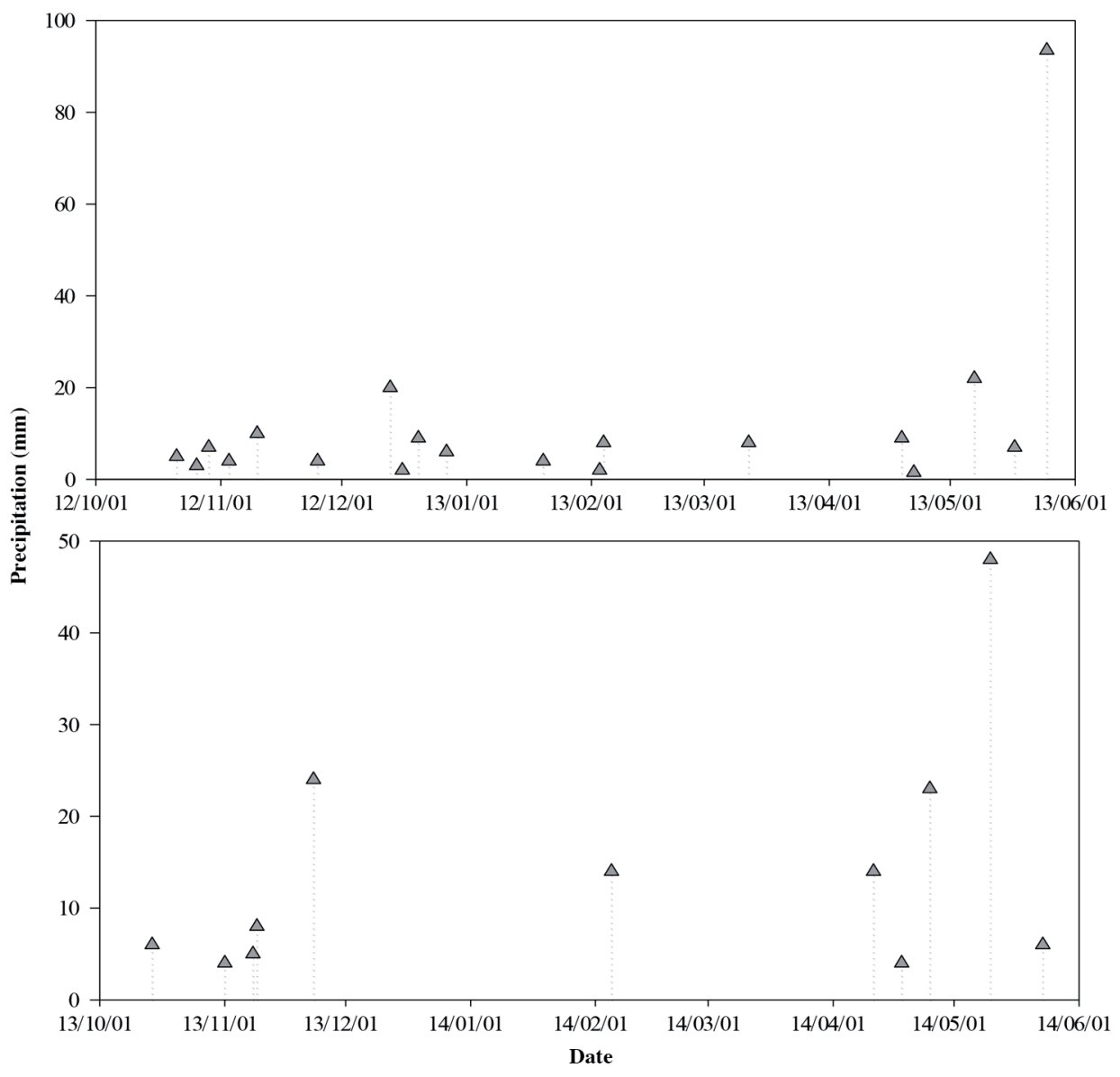




\section{Experimental design}

The SI treatments applied in 2012-2013 and 2013-2014 growing seasons are as follows: in quota SI treatment (W1), $60 \mathrm{~mm}$ water was applied each time; in soil moisture testing SI treatment (W2), water was applied based on the relative soil water content $(\mathrm{SWC})$ of $0-40 \mathrm{~cm}$ soil layer, and the target relative SWC was $70 \%$ field capacity (FC). Field capacity is the amount of soil moisture after draining excess water, and the rate of downward movement has materially decreased (Twarakavi et al., 2009). An SI event occurred the next day after the relative SWC of 0-40 cm soil layer was tested at the jointing (Z31, first node is detectable) and anthesis (Z61, beginning of anthesis) stages (Zadoks et al., 1974). In SI treatments, water was sprayed evenly onto the experimental plots under pressure, and a flow meter was used to measure the amount of applied water. A nonirrigated treatment (W0) was set as control. Table 2 shows SI under different treatments.

The SI amount (I, mm) in W2 was calculated according to the following equation (Guo et al., 2015):

$$
I=10 \times \gamma_{b d} \times D_{h} \times\left(\theta_{t}-\theta_{n}\right)
$$

where $\gamma_{b d}$ is the soil bulk density $\left(\mathrm{g} \mathrm{cm}^{-3}\right), D_{h}$ is the thickness of the soil profile measured for relative SWC before irrigation $(\mathrm{cm}), \theta_{t}$ is the target $\mathrm{SWC}$ on a weight basis after SI (\%), and $\theta_{n}$ is the actual SWC on a weight basis before irrigation (\%). The value of $\theta_{t}$ was calculated as follows:

$$
\theta_{t}=\theta_{\max } \times \theta_{t r}
$$

where $\theta_{\max }$ is the FC (\%) and $\theta_{t r}$ is the target relative SWC $(\%)$.

On the third day after SI, soil samples of 0-40 $\mathrm{cm}$ layer were collected to calculate the relative error between the actual and target relative SWC, each sample was replicated three times. The average relative errors in W2 were $2.23 \%$ and $2.12 \%$ (Table 2) in 2012-2013 and 2013-2014, respectively. These values indicated that the soil moisture testing SI had achieved the target relative SWC.

The experiment plots were in a randomized block design to remove the variability of soil fertility. Each experimental plot was $4 \mathrm{~m} \times 4 \mathrm{~m}$ and replicated three times. A $2.0 \mathrm{~m}$ zone was set between adjacent plots to minimize the effects of other treatments. All plots were supplied with $240 \mathrm{~kg} \mathrm{~N}$ $\mathrm{ha}^{-1}, 150 \mathrm{~kg} \mathrm{P}_{2} \mathrm{O}_{5} \mathrm{ha}^{-1}$, and $150 \mathrm{~kg} \mathrm{~K}_{2} \mathrm{O} \mathrm{ha}{ }^{-1}$. All P and $\mathrm{K}$ fertilizers and $105 \mathrm{~kg} \mathrm{~N}^{-1}$ of $\mathrm{N}$ fertilizers were surfaceapplied to the soil before performing tillage practices. At the jointing stage, $135 \mathrm{~kg} \mathrm{~N} \mathrm{ha}^{-1}$ was applied as a topdressing to the soil at a depth of $4 \mathrm{~cm}$ by ditching between rows of wheat. The high-yield wheat 'Jimai22' was used in the experiments. Wheat seeds were sown using a $2 \mathrm{BJK}-8$ seeder (Yuncheng County Gongli, Heze, China) at a density of $1.8 \times 10^{6}$ seeds ha ${ }^{-1}$ on 9 October 2012 and 9 October 2013 and then harvested on 14 June 2013 and 6 June 2014, respectively.

\section{Sample and data collection}

Soil bulk density and SWC. The soil bulk density of 0-200 $\mathrm{cm}$ soil layers was determined using the method described by Wang et al. (2014b). Samples of 0-200 cm topsoil were collected in all experimental plots by using a soil auger at $20 \mathrm{~cm}$ increments, each sample was replicated three times. SWC on a weight basis was calculated using the oven drying method (Jia et al., 2012). Measurements were performed before sowing (Z00), $1 \mathrm{~d}$ before irrigation and 3 $\mathrm{d}$ after irrigation at both jointing (Z31) and anthesis (Z61) stages, and at maturity (Z90) stage.

Flag leaf photosynthesis parameters. Net photosynthesis rate $\left(\mathrm{P}_{\mathrm{n}}\right)$, stomatal conductance $\left(\mathrm{g}_{\mathrm{s}}\right)$, and transpiration rate $\left(T_{r}\right)$ in flag leaf were observed from 09:00 to 11:00 h under natural light by using a portable photosynthesis system (CIRAS-2, PP-Systems, Hitchin, UK). Five measurements were obtained at 7-d intervals from 0 to $28 \mathrm{~d}$ after anthesis (DAA).

Dry matter production. Samples of the aerial plant parts were collected to monitor DM at anthesis (Z61) and maturity (Z90). Twenty adjacent plants in each plot were randomly cut at ground level and served as one sample. These plants were separated into stem + sheath, spike, and leaf at anthesis. At maturity, they were separated as stem + sheath, leaf, spike axis + glume, and grain. All samples were dried to a constant weight in a forced-draught oven at $70{ }^{\circ} \mathrm{C}$, and their dry weights were recorded. The plant density was computed as the mean plant number within a $1 \mathrm{~m}^{2}$ plot.

The parameters related to DM accumulation and remobilization in wheat plants were calculated as follows (Zhang et al., 2008):

DM accumulation post-anthesis $\left(\mathrm{DMA}_{\mathrm{p}}, \mathrm{kg} \mathrm{ha}^{-1}\right)=\mathrm{DM}$ entire plant at anthesis stage - DM at maturity stage.

Table 2. Target relative soil water content, relative soil water content after irrigation, relative error and irrigation amounts in $0-40$

\begin{tabular}{|c|c|c|c|c|c|c|c|c|c|}
\hline \multirow{2}{*}{$\begin{array}{l}\text { Growing } \\
\text { seasons }\end{array}$} & \multirow[b]{2}{*}{ Treatments } & \multicolumn{4}{|c|}{ Jointing stage } & \multicolumn{4}{|c|}{ Anthesis stage } \\
\hline & & TSRWC & RWCAI & $\mathrm{RE}$ & I & TSRWC & RWCAI & $\mathrm{RE}$ & I \\
\hline & & +2 & $\%$ & 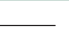 & $\mathrm{mm}$ & 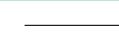 & $\%$ & - & $\mathrm{mm}$ \\
\hline \multirow[t]{3}{*}{$2012-2013$} & W0 & - & - & - & 0.00 & - & - & - & 0.00 \\
\hline & W1 & - & 70.93 & - & 60.00 & - & 77.36 & - & 60.00 \\
\hline & W2 & 70 & 67.74 & 3.23 & 56.98 & 70 & 69.14 & 1.23 & 50.06 \\
\hline \multirow[t]{3}{*}{ 2013-2014 } & W0 & - & - & - & 0.00 & - & - & - & 0.00 \\
\hline & W1 & - & 67.52 & - & 60.00 & - & 95.42 & - & 60.00 \\
\hline & $\mathrm{W} 2$ & 70 & 68.27 & 2.47 & 61.63 & 70 & 68.76 & 1.77 & 14.96 \\
\hline
\end{tabular}
cm soil layers of different treatments.

TSRWC: Target soil relative water content; RWCAI: relative soil water content after irrigation; RE: relative error; I: irrigation amount. 
DM remobilization amount pre-anthesis $\left(\mathrm{DMR}, \mathrm{kg} \mathrm{ha}^{-1}\right)=$ DM plant aerial part at anthesis stage - (DM stem + sheath + leaf + spike axis + glume at maturity)

Contribution $\mathrm{DMA}_{\mathrm{p}}$ to grain $\left(\mathrm{GCDMA}_{\mathrm{p}}, \%\right)=\left(\mathrm{DMA}_{\mathrm{p}} /\right.$ $\mathrm{DM}$ grains at maturity) $\times 100$

Contribution DMR to grain $(\mathrm{GCDMR}, \%)=(\mathrm{DMR} / \mathrm{DM}$ grains at maturity) $\times 100$

Labelling of selected flag leaves with ${ }^{13} \mathrm{CO}_{2}$. In 2013 2014 growing season, 10 flag leaves in each treatment were selected to be labelled with ${ }^{13} \mathrm{CO}_{2}$ at 14 DAA. The flag leaf was overlapped by a $0.1-\mathrm{mm}$ thick Mylar plastic bag, which could pass more than $95 \%$ of sunlight through. The bags were sealed with plasticine and then injected with 3.5 $\mathrm{mL}{ }^{13} \mathrm{CO}_{2}$. After $30 \mathrm{~min}$ of photosynthesis, the remaining radioactive ${ }^{13} \mathrm{CO}_{2}$ was absorbed by a $\mathrm{NaOH}$ washer, and the plastic bag was removed. The labelled samples were collected at ground level from 10 single tillers at maturity (Z90). Each tiller was separated into five parts as follows: flag leaves, other leaves, stem + sheath, spikes + glumes, and grain. All of the samples were oven-dried at $70{ }^{\circ} \mathrm{C}$ to a constant weight, and then their DM (g) values were recorded. The samples were subsequently milled into powder. Approximately $4 \mathrm{mg}$ of samples were weighed and placed in tin capsules to determine their isotopic abundance by using a stable isotope ratio mass spectrometer (IsoPrime100, Isoprime, Cheadle, UK). Carbon isotope data were expressed in the typical delta notation $\left(\delta^{13} \mathrm{C}\right)$, which is defined as follows (Yousfi et al., 2012):

$$
\delta{ }^{13} \mathrm{C}(\%)=\left(\frac{R_{\text {sample }}}{R_{\text {standard }}} 1\right) \times 1000
$$

where $R$ is the ${ }^{13} \mathrm{C} /{ }^{12} \mathrm{C}$ isotope ratio. The international standard for $\mathrm{C}$ is Pee Dee Belemnite with a ${ }^{13} \mathrm{C} /{ }^{12} \mathrm{C}\left(R_{P D B}\right)$ ratio of 0.01112372 .

Atomic ${ }^{13} \mathrm{C} \%$ was calculated as follows (Li et al., 2012):

$$
\text { Atomic }{ }^{13} C(\%)=\frac{\left(\delta^{13} C+1000\right) \times R_{P B D}}{\left(\delta^{13} C+1000\right) \times R_{P B D}+1000} \times 100
$$

The assimilated ${ }^{13} \mathrm{C}$ in different organs was estimated as the difference between ${ }^{13} \mathrm{C}$ contents of the labelled and nonlabelled samples, as follows ( $\mathrm{Lu}$ et al., 2002):

$$
{ }^{13} C_{s}=\left(\text { atomic }{ }^{13} C_{l}-\text { atomic }{ }^{13} C_{n l}\right) \times T C_{s} \times D M_{s} \times 100
$$

where ${ }^{13} C_{s}$ is ${ }^{13} \mathrm{C}$ assimilation in different organs (mg), atomic ${ }^{13} C_{l}$ and atomic ${ }^{13} C_{n l}$ indicate the atomic ${ }^{13} \mathrm{C}$ of labelled and non-labelled samples (\%), respectively; $T C_{s}$ is the total $\mathrm{C}$ content of sample (\%), and $D M_{s}$ is the dry weight of the sample $(\mathrm{kg})$.

Net ${ }^{13} \mathrm{C}$ assimilation of the entire plant is the sum of net ${ }^{13} \mathrm{C}_{\mathrm{S}}$ in flag leaves, other leaves, stem + sheath, spikes + glumes, and grain. The ${ }^{13} \mathrm{C}$ distribution ratio of different organs was calculated as the ratio of ${ }^{13} \mathrm{C}_{\mathrm{s}}$ to net ${ }^{13} \mathrm{C}$ assimilation of the entire plant (Lu et al., 2002).

ET and WUE. The total water consumption or crop ET during the growing season was calculated using the soil water balance equation (Patanè and Cosentino, 2013):

$$
E T=P+I+\Delta W-R-D
$$

where $E T(\mathrm{~mm})$ is the total water consumption during growing season, $P(\mathrm{~mm})$ is the precipitation, $I(\mathrm{~mm})$ is the SI amount, $\Delta W(\mathrm{~mm})$ is the soil water storage at sowing minus the soil water storage at harvesting for the $0-200 \mathrm{~cm}$ soil profile, $R(\mathrm{~mm})$ is the surface runoff, and $D(\mathrm{~mm})$ is the downward flux below the crop root zone. Run off and drainage are ignored in the North China Plain (including this experimental site, Lv et al., 2011).

WUE $\left(\mathrm{kg} \mathrm{ha}^{-1} \mathrm{~mm}^{-1}\right)$ is defined as follows (Wang et al., 2013):

$$
W U E=Y / E T
$$

where $Y\left(\mathrm{~kg} \mathrm{ha}^{-1} \mathrm{~mm}^{-1}\right)$ is the grain yield and $E T(\mathrm{~mm})$ is the total water consumption during a growing season.

\section{Statistical analyses}

Data were statistically analyzed by using ANOVA and Fisher's Least Significance Difference test (LSD) as the multiple pairwise comparison at $\alpha=0.05$ to determine the significant effects of the treatments (SPSS 13.0 software).

\section{RESULTS AND DISCUSSION}

\section{Relative SWC of 0-200 cm soil layers at jointing, anthesis, and maturity stages}

Soil water condition at different growth stages affects photosynthetic characteristics, DM accumulation, and grain yield, which are directly affected by amount of irrigation (Liu et al., 2016). In our study, the average irrigation amounts in W1 and W2 in the two growing season were 60 and $59.31 \mathrm{~mm}$ at the jointing stage and 60 and $32.51 \mathrm{~mm}$ at the anthesis stage, respectively (Table 2). At jointing post-irrigation, the relative $\mathrm{SWC}$ of $0-40 \mathrm{~cm}$ soil layer was significantly higher in SI treatments (W1 and W2) than in W0 in both growing seasons (Figure 2). Nonsignificant difference was observed in the relative SWC of $60-200 \mathrm{~cm}$ soil layer among the treatments. At anthesis post-irrigation, W1 obtained the highest average relative SWC of 0-40 cm and $60-160 \mathrm{~cm}$ soil layer during the two growing season, followed by W2, W0 was the lowest, and the difference was significant. At maturity, in 2012-2013 growing season, the relative SWC in $80-180 \mathrm{~cm}$ soil layer of W1 was significantly higher than that of $\mathrm{W} 2$, W0 obtained the significant lowest relative SWC in $80-180 \mathrm{~cm}$ soil layer in comparison of W1 and W2. In 2013-2014 growing season, W1 produced the highest relative SWC in $80-160 \mathrm{~cm}$ soil layer at maturity, followed by W2 and W0, the difference was significant. This result showed that a decreasing irrigation amount increased water use in deep soil layer, consistent with the finding of Liu et al. (2011).

\section{Net photosynthetic rate, stomatal conductance, and transpiration of flag leaf}

Compared with the SI in W0, that at the jointing and anthesis stages in $\mathrm{W} 1$ and $\mathrm{W} 2$ increased the average flag leaf net photosynthetic rate, stomatal conductance, and transpiration in grain filling stage by $77.3 \%, 66.1 \%$, 
Figure 2. Relative soil water content of different treatments at jointing and anthesis post-irrigation and maturity in $2012-2013$ and 2013-2014 growing seasons.

Relative soil water content (\%)

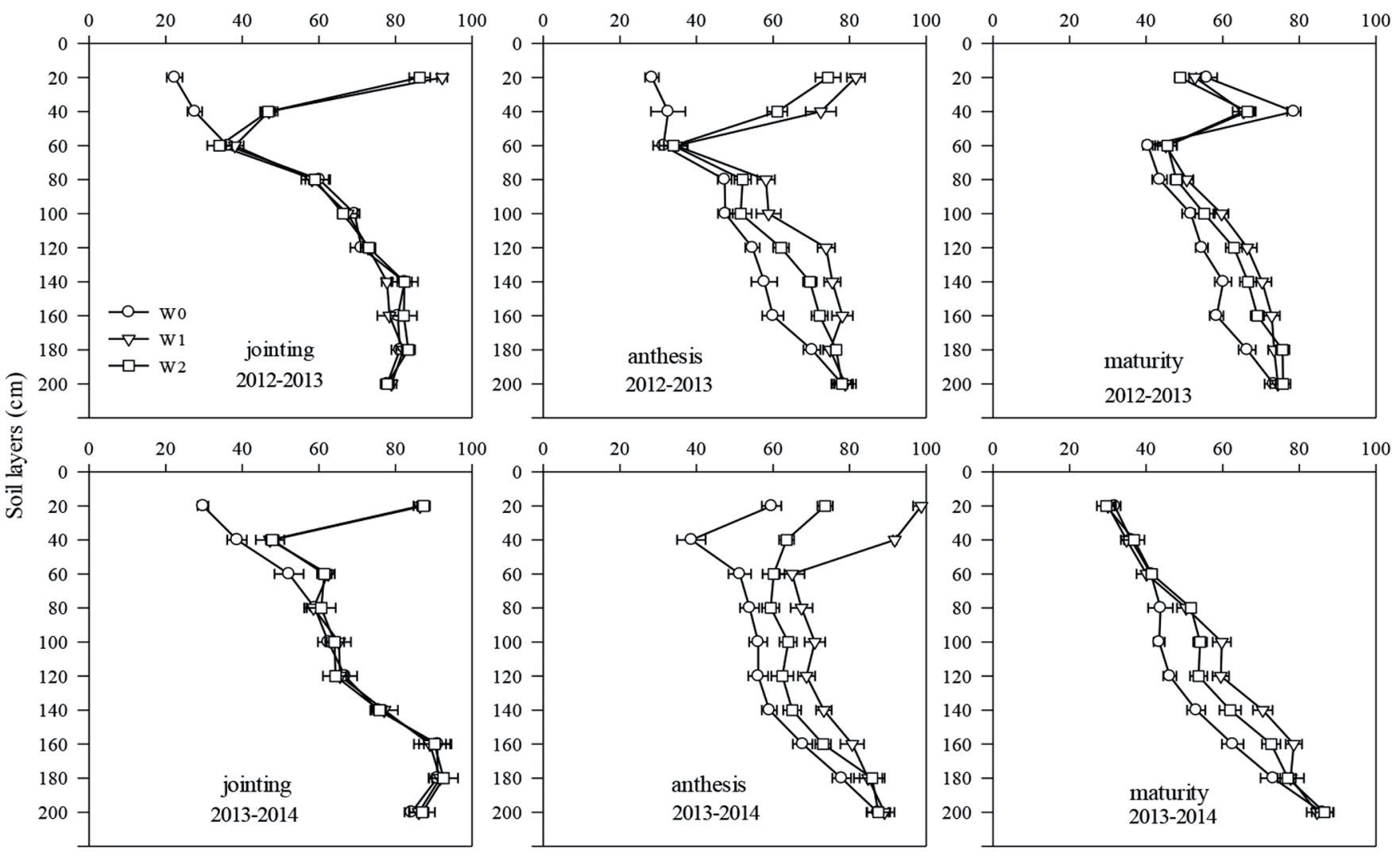

Error bars represent standard errors of the means $(\mathrm{P}<0.05)$.

and $51.9 \%$ in the two growing seasons, respectively (Figure 3). Similar results were reported by Xue et al. (2006), implying that non-irrigated treatment reduces the photosynthetic rate and stomatal conductance in flag leaf. Kang et al. (2002) and Wang et al. (2013) reported that reduced irrigation and the application of fertilizer maintain the high photosynthetic capacity of wheat and reduce ET, resulting in high grain yield and WUE. Compared with the wheat grown under full irrigation condition (75\%-80\% FC), that grown under mild drought stress condition (65\%$70 \%$ of FC) during recovering to jointing stage maintains high canopy photosynthesis after anthesis (Liu et al., 2016). Our study found that setting the relative SWC of $0-40 \mathrm{~cm}$ soil layer to $70 \%$ both at the jointing and anthesis stages (W2) increased the net photosynthetic rate by $7.5 \%$, $9.6 \%$, and $21.4 \%$ at 14,21 , and 28 DAA compared with that in quota SI treatment (W1) during the 2012-2013 growing season. Gas exchange controlled by stomata is essential in maintenance of photosynthetic capacity (Oliver et al., 2009). Significant increase in stomatal conductance (11.7\%, 6.3\%, and 9.5\% at 14, 21, and 28 DAA) and transpiration $(10.8 \%, 7.6 \%$, and $30.9 \%$ at 14,21 , and 28 DAA) was observed in W2 but not in W1, indicating that the photosynthetic reduction in $\mathrm{W} 1$ was due to stomatal conductance. A similar pattern was observed in $\mathrm{W} 0, \mathrm{~W} 1$, and W2 in the 2013-2014 growing season.
Dry matter accumulation in different organs at anthesis and maturity stages

Dry matter accumulation and photosynthetic activity both influence wheat grain yield (Liang et al., 2010), which are associated with irrigation and SWC (Boutraa et al., 2010). Meng et al. (2013) found that DM at the regreening, stem elongation, anthesis, and maturity stages are all significantly correlated with grain yield, and the increase in grain yield from 7-9 $\mathrm{t} \mathrm{ha}^{-1}$ to $>9 \mathrm{t} \mathrm{ha}^{-1}$ is mainly attributed to the increase in DM from stem elongation to anthesis stage. Compared with $\mathrm{W} 1$ and $\mathrm{W} 2$, W0 reduced the average total DM content in the two growing seasons by $32.15 \%$ in anthesis stage, and this phenomenon is mainly caused by DM reduction in stem + sheath (Table 3 ). Dry matter contents in stem + sheath, leaves, and spikes of $\mathrm{W} 2$ were greater by $1.71 \%, 3.05 \%$, and $1.20 \%$ than those in $\mathrm{W} 1$ in 2012-2013 growing season and greater by $1.37 \%, 2.79 \%$, and $2.17 \%$ than those in W1 in 2013-2014 growing season. Eventually, total DM in W2 increased by 217.66 and 253.75 $\mathrm{kg} \mathrm{ha}^{-1}$ compared with that in W1 in 2012-2013 and 20132014 growing seasons, respectively, although the difference was nonsignificant possibly due to the similar irrigation amount at jointing stages in W1 and W2.

At maturity, DM accumulation was highest in grain followed by those in stem + sheath, leaves, and spike axis + glume (Table 4). Moreover, W0 reduced DM in 
Figure 3. Photosynthetic rate $\left(P_{n}\right)$, stomatal conductance $\left(g_{s}\right)$ and transpiration rate $\left(T_{r}\right)$ post-anthesis in 2012-2013 and $2013-2014$ growing seasons.
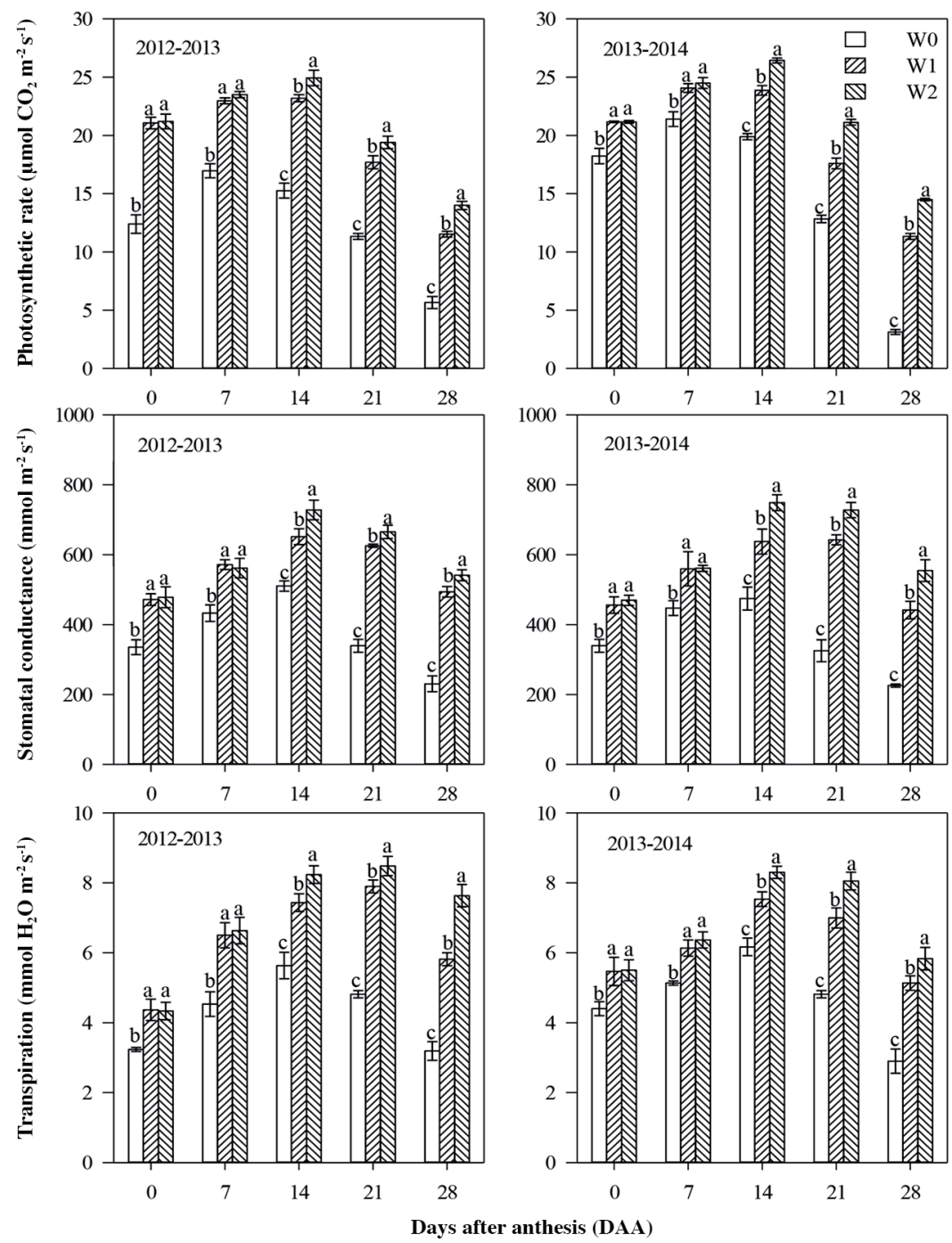

Values with different letters above error bars represent significant difference according to LSD test $(\mathrm{P}<0.05)$.

different organs compared with irrigation treatments, consistent with the results of Zhao et al. (2013). Kang et al. (2002) showed that setting SWC to 55\% FC from the regrowth to stem elongation stages, to $70 \% \mathrm{FC}$ from the booting stage to milk ripeness stage, and to $45 \%$ $55 \%$ FC from maturity to harvest obtained high biomass (DM at maturity), grain yield and WUE of wheat in

Table 3. Dry matter accumulation of different organs at anthesis.

\begin{tabular}{|c|c|c|c|c|c|}
\hline \multirow{2}{*}{$\begin{array}{l}\text { Growing } \\
\text { seasons }\end{array}$} & \multirow[b]{2}{*}{ Treatments } & \multicolumn{3}{|c|}{ Organs } & \multirow[b]{2}{*}{ Total } \\
\hline & & Stem + sheath & Leaves & Spikes & \\
\hline & & & - $\mathrm{kg}$ ha & & \\
\hline \multirow[t]{3}{*}{$2012-2013$} & W0 & $4799.60 \mathrm{~b}$ & $1627.60 \mathrm{~b}$ & $1835.60 \mathrm{~b}$ & $8262.80 \mathrm{~b}$ \\
\hline & W1 & $7614.07 \mathrm{a}$ & 2012.19a & 2194.48a & $11820.73 a$ \\
\hline & W2 & $7744.00 \mathrm{a}$ & $2073.60 \mathrm{a}$ & $2220.80 \mathrm{a}$ & $12038.40 \mathrm{a}$ \\
\hline \multirow[t]{3}{*}{ 2013-2014 } & W0 & $5744.23 b$ & $1823.03 b$ & $1860.20 \mathrm{~b}$ & $9427.46 \mathrm{~b}$ \\
\hline & W1 & $8614.91 \mathrm{a}$ & $2856.22 \mathrm{a}$ & $2590.25 \mathrm{a}$ & $14061.38 \mathrm{a}$ \\
\hline & W2 & $8732.69 a$ & $2935.99 a$ & $2646.45 \mathrm{a}$ & $14315.13 a$ \\
\hline
\end{tabular}

Within a column, values in the same growing season followed by different letters differ significantly $(\mathrm{P}<0.05)$. Same as Tables 4, 6 and 7 .
Loess Plateau of China. In our study, DM content in stem + sheath, leaves, spikes axis + glume, and grain in W2 increased by $7.86 \%, 5.17 \%, 11.89 \%$, and $5.74 \%$ in 2012-2013 growing season and by $6.64 \%, 5.61 \%, 6.26 \%$, and 5.90\% in 2013-2014 growing season, respectively, compared with that in W1. Eventually, total DM in

Table 4. Dry matter accumulation of different organs at maturity.

\begin{tabular}{|c|c|c|c|c|c|c|}
\hline \multirow[b]{2}{*}{$\begin{array}{l}\text { Growing } \\
\text { seasons }\end{array}$} & \multirow[b]{2}{*}{ Treatments } & \multicolumn{4}{|c|}{ Organs } & \multirow[b]{2}{*}{ Total } \\
\hline & & $\begin{array}{c}\text { Stem } \\
+ \\
\text { sheath }\end{array}$ & Leaves & $\begin{array}{l}\text { Spike } \\
\text { axis }+ \\
\text { glume }\end{array}$ & Grains & \\
\hline & & & & - $\mathrm{kg} \mathrm{ha}^{-1}$ & & \\
\hline \multirow[t]{3}{*}{$2012-2013$} & W0 & $2679.12 \mathrm{c}$ & $1476.20 \mathrm{c}$ & $1239.55 \mathrm{c}$ & $5381.37 \mathrm{c}$ & $10776.24 \mathrm{c}$ \\
\hline & W1 & $6175.56 b$ & $1676.33 \mathrm{~b}$ & $1552.91 \mathrm{~b}$ & $7941.55 b$ & $17346.34 b$ \\
\hline & $\mathrm{W} 2$ & $6661.07 \mathrm{a}$ & $1763.14 \mathrm{a}$ & $1737.67 \mathrm{a}$ & $8397.37 a$ & $18559.25 \mathrm{a}$ \\
\hline \multirow[t]{3}{*}{ 2013-2014 } & W0 & $3442.99 \mathrm{c}$ & $1806.14 \mathrm{c}$ & $1404.81 \mathrm{c}$ & $6354.25 \mathrm{c}$ & $13008.19 \mathrm{c}$ \\
\hline & W1 & $7770.26 \mathrm{~b}$ & $2017.70 b$ & $1768.76 b$ & $8509.50 \mathrm{~b}$ & $20066.22 b$ \\
\hline & W2 & 8286.21a & $2130.96 a$ & $1879.44 a$ & $9011.70 a$ & $21308.31 \mathrm{a}$ \\
\hline
\end{tabular}


W2 increased by $6.99 \%$ and $6.19 \%$ relative to that in $\mathrm{W} 1$ in 2012-2013 and 2013-2014 growing seasons, respectively. Moreover, ${ }^{13} \mathrm{C}$ accumulation amount and ratio (Table 5) demonstrates that $\mathrm{W} 2$ increased the total ${ }^{13} \mathrm{C}$ assimilation amount. ${ }^{13} \mathrm{C}$ accumulation amount and ratio in grain at maturity were larger by $277.0 \%$ and $9.7 \%$ than those in W0 and larger by $63.8 \%$ and $3.7 \%$ than those in W1 during the same labeling time.

\section{Dry matter remobilization amount and ratio to grain at pre-anthesis stage}

The enhanced DM accumulation at maturity and high contribution ratio of DM accumulation post-anthesis $\left(\mathrm{DMA}_{\mathrm{p}}\right)$ to grain resulted in high wheat grain yield in Huang-Huai-Hai Plain (Zhang et al., 2008). Appropriate irrigation increases $\mathrm{DMA}_{\mathrm{p}}$ and improves the $\mathrm{DMA}_{\mathrm{p}}$ contribution to grain (Ercoli et al., 2008; Liu and Ouyang, 2012). Ma et al. (2014) indicated that drought stress reduces grain yield by reducing $\mathrm{DMA}_{\mathrm{p}}$, which contributes approximately $87 \%, 82 \%$, and $63 \%$ to grain yield under non-stress, moderate, and severe stress conditions, respectively. Table 6 shows the DM remobilization amount at pre-anthesis stage and accumulation amount at postanthesis stage and their contribution ratio to grain. In both growing seasons, W2 reduced DM remobilization amount and its contribution ratio at pre-anthesis stage by $30.90 \%$ and $53.37 \%$, respectively, compared with W0 and

Table $5 .{ }^{13} \mathrm{C}$ accumulation amount and ratio in different organs at maturity in 2013-2014 growing season.

\begin{tabular}{lcccc}
\hline \multicolumn{2}{c}{ Treatments } & $\mathrm{W} 0$ & $\mathrm{~W} 1$ & $\mathrm{~W} 2$ \\
\hline${ }^{13} \mathrm{C}$ accumulation & Flag leaves & $0.0008 \mathrm{c}$ & $0.0013 \mathrm{~b}$ & $0.0021 \mathrm{a}$ \\
amount in different & Other leaves & $0.0002 \mathrm{c}$ & $0.0003 \mathrm{~b}$ & $0.0004 \mathrm{a}$ \\
organs, mg & Steam + sheath & $0.0007 \mathrm{c}$ & $0.0017 \mathrm{~b}$ & $0.0019 \mathrm{a}$ \\
& Spike axis + glumes & $0.0004 \mathrm{~b}$ & $0.0006 \mathrm{a}$ & $0.0006 \mathrm{a}$ \\
& Grain & $0.0070 \mathrm{c}$ & $0.0161 \mathrm{~b}$ & $0.0264 \mathrm{a}$ \\
& Total & $0.0091 \mathrm{c}$ & $0.0200 \mathrm{~b}$ & $0.0314 \mathrm{a}$ \\
${ }^{13} \mathrm{C}$ accumulation & Flag leaves & $8.79 \mathrm{a}$ & $6.50 \mathrm{~b}$ & $6.69 \mathrm{~b}$ \\
ratio in different & Other leaves & $2.20 \mathrm{a}$ & $1.50 \mathrm{~b}$ & $1.27 \mathrm{c}$ \\
organs, \% & Steam + sheath & $7.69 \mathrm{~b}$ & $8.50 \mathrm{a}$ & $6.05 \mathrm{c}$ \\
& Spike axis + glumes & $4.40 \mathrm{a}$ & $3.00 \mathrm{~b}$ & $1.91 \mathrm{c}$ \\
& Grain & $76.92 \mathrm{c}$ & $80.50 \mathrm{~b}$ & $84.08 \mathrm{a}$ \\
\hline
\end{tabular}

Table 6. Dry matter remobilization (DMR) amount pre-anthesis and accumulation amount post-anthesis $\left(\mathrm{DMA}_{\mathrm{p}}\right)$ and their contribution ratio to grain in 2012-2013 and 2013-2014 growing seasons.

\begin{tabular}{lccccc}
\hline $\begin{array}{l}\text { Growing } \\
\text { seasons }\end{array}$ & Treatments & DMR & GCDMR & DMA $_{\mathrm{p}}$ & GCDMA $_{\mathrm{p}}$ \\
\hline \multirow{2}{*}{$2012-2013$} & & $\mathrm{~kg} \mathrm{ha}^{-1}$ & $\%$ & $\mathrm{~kg} \mathrm{ha}^{-1}$ & $\%$ \\
& $\mathrm{~W} 0$ & $2867.93 \mathrm{a}$ & $53.29 \mathrm{a}$ & $2513.44 \mathrm{c}$ & $46.71 \mathrm{c}$ \\
& $\mathrm{W} 1$ & $2415.93 \mathrm{~b}$ & $30.42 \mathrm{~b}$ & $5525.61 \mathrm{~b}$ & $69.58 \mathrm{~b}$ \\
$2013-2014$ & $\mathrm{~W} 2$ & $1876.52 \mathrm{c}$ & $22.35 \mathrm{c}$ & $6520.85 \mathrm{a}$ & $77.65 \mathrm{a}$ \\
& $\mathrm{W} 0$ & $2773.52 \mathrm{a}$ & $43.65 \mathrm{a}$ & $3580.73 \mathrm{c}$ & $56.35 \mathrm{c}$ \\
& $\mathrm{W} 1$ & $2504.66 \mathrm{~b}$ & $29.43 \mathrm{~b}$ & $6004.84 \mathrm{~b}$ & $70.57 \mathrm{~b}$ \\
& $\mathrm{~W} 2$ & $2018.52 \mathrm{c}$ & $22.40 \mathrm{c}$ & $6993.18 \mathrm{a}$ & $77.60 \mathrm{a}$ \\
\hline
\end{tabular}

GCDMR: Contribution of DM remobilization to grain; GCDMA contribution of DM accumulation post-anthesis to grain.

Within a row, values in the same growing season followed by different letters differ significantly $(\mathrm{P}<0.05)$. by $20.87 \%$ and $25.21 \%$ compared with W1. Moreover, DM accumulation amount at post-anthesis stage and its contribution ratio to grain in W2 were larger by $127.37 \%$ and $51.97 \%$ in W0 and by $17.24 \%$ and $10.80 \%$ than in $\mathrm{W} 1$. These results indicate that the increase in DM accumulation amount post-anthesis was the main factor for the increase in grain yield.

\section{Grain yield, WUE, and irrigation benefit}

Studies have shown that ET of wheat decreased with reduced irrigation amount, and non-irrigated treatment generally results in low ET and grain yield but high WUE compared with irrigation treatments (Guo et al., 2008; Dong et al., 2013). In our study, W0 reduced ET, grain yield, and WUE compared with SI treatments in both 20122013 and 2013-2014 growing seasons (Table 7), consistent with the findings of Yu et al. (2010). Moreover, Yu et al. (2010) found that a quadratic relationship exists between wheat grain yield, WUE, and water consumption, and increased grain yield and WUE were obtained when the ET ranged from 350 to $490 \mathrm{~mm}$. Compared with well-watered condition, moderate water deficiency at grain filling stage resulted in high grain yield and WUE, corresponding to the increased DM mobilization and low ET (Zhang et al., 2008). Under mobile rain shelter condition, setting the relative SWC to $65 \%-70 \% \mathrm{FC}$ at the grain filling stage resulted in the highest grain yield and WUE compared with that obtained under $75 \%-80 \%$ FC treatment (Liu et al., 2016). In our study, the ET of treatment which bring relative SWC to $70 \%$ at jointing and anthesis stage (W2) was 410.16 and $424.14 \mathrm{~mm}$, which decreased by 2.47 and $28.42 \mathrm{~mm}$ than treatment which irrigate $60 \mathrm{~mm}$ water at jointing and anthesis stage (W1) due to the 12.96 and 43.41 $\mathrm{mm}$ reduction of SI in 2012-2013 and 2013-2014 growing season, respectively. Moreover, the grain yields in W2 were higher by $5.7 \%$ and $5.9 \%$ than in W1. Thus, the WUE and IB were significantly higher in W2 than in W1.

Table 7. Grain yield, total irrigation amount, evapotranspiration (ET), water use efficiency (WUE) and irrigation benefit (IB) of different treatments.

\begin{tabular}{lccccccc}
\hline $\begin{array}{l}\text { Growing } \\
\text { seasons }\end{array}$ & Treatments & $\begin{array}{c}\text { Grain } \\
\text { yield }\end{array}$ & $\begin{array}{c}\text { Total } \\
\text { irrigation } \\
\text { amount }\end{array}$ & ET & WUE & IB \\
\hline \multirow{2}{*}{$2012-2013$} & W0 & 5381.37c & 0.00 & $332.08 \mathrm{~b}$ & $16.20 \mathrm{c}$ & - \\
& W1 & $7941.55 \mathrm{~b}$ & $120.00 \mathrm{a}$ & $412.63 \mathrm{a}$ & $19.25 \mathrm{~b}$ & $21.33 \mathrm{~b}$ \\
& $\mathrm{~W} 2$ & $8397.37 \mathrm{a}$ & $107.04 \mathrm{~b}$ & $410.16 \mathrm{a}$ & $20.47 \mathrm{a}$ & $28.18 \mathrm{a}$ \\
$2013-2014$ & W0 & $6354.25 \mathrm{c}$ & 0.00 & $383.47 \mathrm{c}$ & $16.57 \mathrm{c}$ & - \\
& W1 & $8509.50 \mathrm{~b}$ & $120.00 \mathrm{a}$ & $452.56 \mathrm{a}$ & $18.80 \mathrm{~b}$ & $17.96 \mathrm{~b}$ \\
& $\mathrm{~W} 2$ & $9011.70 \mathrm{a}$ & $76.59 \mathrm{~b}$ & $424.14 \mathrm{~b}$ & $21.25 \mathrm{a}$ & $34.70 \mathrm{a}$ \\
\hline
\end{tabular}

\section{CONCLUSIONS}

In this study, soil moisture testing supplemental irrigation (SI) (W2) reduced the SI amount, thereby increasing water uptake in $80-160 \mathrm{~cm}$ soil layers and reducing evapotranspiration. 
The flag leaf in W2 maintained high photosynthetic rate, stomatal conductance, and transpiration at the late grain filling stage. Therefore, dry matter at maturity, dry matter accumulation post-anthesis and its contribution ratio to grain were significantly higher in W2 than in other treatments. Consequently, W2 achieved the highest grain yield, water use efficiency, and irrigation benefit. In conclusion, soil moisture testing SI based on $0-40 \mathrm{~cm}$ layer with a relative soil water content of $70 \%$ field capacity at the jointing and anthesis stages was the most suitable irrigation strategy considering high yield and water conservation.

\section{ACKNOWLEDGEMENTS}

This work was supported by the National Natural Science Foundation of China (31401334), the National Agriculture Technology Research System of China (CARS-3-1-19).

\section{REFERENCES}

Bahrani, A., Sharif-Abad, H.H., Sarvestani, Z.T., Moafpourian, G.H., and Band, A.A. 2011. Remobilization of dry matter in wheat: effects of nitrogen application and post-anthesis water deficit during grain filling. New Zealand Journal of Crop and Horticultural Science 39:279-293.

Boutraa, T., Akhkha, A., Al-Shoaibi, A.A., and Alhejeli, A.M. 2010. Effect of water stress on growth and water use efficiency (WUE) of some wheat cultivars (Triticum durum) grown in Saudi Arabia. Journal of Taibah University for Science 3:39-48.

Dong, H., Chen, Y.H., and Zhou, X.B. 2013. Effects of irrigation and planting pattern on wheat water consumption characteristics and dry matter production. Chinese Journal of Applied Ecology 24:1871-1878 (in Chinese).

Ercoli, L., Lulli, L., Mariotti, M., Masoni, A., and Arduini, I. 2008. Post-anthesis dry matter and nitrogen dynamics in durum wheat as affected by nitrogen supply and soil water availability. European Journal of Agronomy 28:138-147.

Fan, L., Lv, C.H., Yu, B.H., and Wang, T. 2016. Yield potential and yield gap of wheat-maize cropping system in the North China Plain. Chinese Agricultural Science Bulletin 32:33-40 (in Chinese).

Fang, Q.X., Chen, Y.H., Li, Q.Q., Yu, S.Z., Luo, Y., Yu, Q., et al. 2006. Effects of soil moisture on radiation utilization during late growth stages and water use efficiency of wheat. Acta Agronomic Sinica 32:861-866 (in Chinese).

Fang, Q.X., Ma, L., Green, T.R., Yu, Q., Wang, T.D., and Ahuja, L.R. 2010. Water resources and water use efficiency in the North China Plain: Current status and agronomic management options. Agricultural Water Management 97:1102-1116.

Guo, Z.J., Shi, Y., Yu, Z.W., and Zhang, Y.L. 2015. Supplemental irrigation affected flag leaves senescence post-anthesis and grain yield of wheat in the Huang-Huai-Hai Plain of China. Field Crops Research 180:100-109.

Guo, Y.Q., Wang, L.M., He, X.H., Zhang, X.Y., Chen, S.Y., Chen, J., et al. 2008. Water use efficiency and evapotranspiration of wheat and its response to irrigation regime in the north China plain. Agricultural and Forest Meteorology 148:1848-1859.

Hu, Y., Moiwo, J.P., Yang, Y., Han, S., and Yang, Y. 2010. Agricultural water-saving and sustainable groundwater management in Shijiazhuang Irrigation District, North China Plain. Journal of Hydrology 393:219-232.
Jia, D., Dai, X., and He, M. 2012. Polymerization of glutenin during grain development and quality expression in wheat in response to irrigation levels. Crop Science 52:1816-1827.

Kang, S., Zhang, L., Liang, Y., Hu, X., Cai, H., and Gu, B. 2002. Effects of limited irrigation on yield and water use efficiency of wheat in the Loess Plateau of China. Agricultural Water Management 55:203-216.

Li, J., Jiang, Y.M., Wei, S.C., Zhou, E.D., Chen, R., and Ge, S.F. 2012. Effects of continued pinching on characteristics of utilization and distribution of ${ }^{13} \mathrm{C}$ and ${ }^{15} \mathrm{~N}$ for Red Fuji/SH1/ Malus robusta Rehd. Acta Horticulturae Sinica 39:2238-2244 (in Chinese).

Li, Q., Liu, M., Zhang, J., Dong, B., and Bai, Q. 2009. Biomass accumulation and radiation use efficiency of wheat under deficit irrigation regimes. Plant Soil and Environment 55:85-91.

Liang, Y., Zhang, K.P., Zhao, L., Liu, B., Meng, Q.W., Tian, J.C., et al. 2010. Identification of chromosome regions conferring dry matter accumulation and photosynthesis in wheat (Triticum aestivum L.) Euphytica 171:145-156.

Liu, E., Mei, X., Yan, C., Gong, D., and Zhang, Y. 2016. Effects of water stress on photosynthetic characteristics, dry matter translocation and WUE in two wheat genotypes. Agricultural Water Management 167:75-85.

Liu, L., and Ouyang, Z. 2012. Effects of irrigation schedules on photosynthetic carbon assimilation of wheat (Triticum aestivum L.) in North China Plain: from leaf to population. Journal of Northeast Agricultural University (English edition) 4:20-29.

Liu, K., Zhang, Y., Wang, Z., Feng, H., Zhou, S., Lu, L., et al. 2011. Characteristics of water consumption in water-saving wheat and effects on the utilization of subsequent summer rainfall in the North China Plain. International Journal of Plant Production 2:167-180.

Lu, Y.H., Watanabe, A., and Kimura, M. 2002. Input and distribution of photosynthesized carbon in a flooded rice soil. Global Biogeochemical Cycles 16:32-31. doi:10.1029/2002GB001864.

Lv, L.H., Wang, H.J., Jia, X.L., and Wang, Z.M. 2011. Analysis on water requirement and water-saving amount of wheat and corn in typical regions of the North China Plain. Frontiers Agriculture in China 5:556-562.

Ma, J., Huang, G., Yang, D., and Chai, Q. 2014. Dry matter remobilization and compensatory effects in various internodes of spring wheat under water stress. Crop Science 54:331.

Meng, Q., Yue, S., Chen, X., Cui, Z., Ye, Y., Ma, W., et al. 2013. Understanding dry matter and nitrogen accumulation with timecourse for high-yielding wheat production in China. PLOS ONE 8:e68783.

Oliver, R.J., Finch, J.W., and Taylor, G. 2009. Second generation bioenergy crops and climate change: a review of the effects of elevated atmospheric $\mathrm{CO}_{2}$ and drought on water use and the implications for yield. CGB Bioenergy 1:97-114.

Patanè, C., and Cosentino, S.L. 2013. Yield, water use and radiation use efficiencies of kenaf (Hibiscus cannabinus L.) under reduced water and nitrogen soil availability in a semi-arid Mediterranean area. European Journal of Agronomy 46:53-62.

Plaut, Z., Butow, B.J., Blumenthal, C.S., and Wrigley, C.W. 2004. Transport of dry matter into developing wheat kernels and its contribution to grain yield under post-anthesis water deficit and elevated temperature. Field Crops Research 86:185-198.

Sun, Q., Kröbel, R., Müller, T., Römheld, V., Cui, Z., and Zhang, F. 2011. Optimization of yield and water-use of different cropping systems for sustainable groundwater use in North China Plain. Agricultural Water Management 98:808-814. 
Twarakavi, N.K.C., Sakai, M., and Simunek, J. 2009. An objective analysis of the dynamic nature of field capacity. Water Resource Research 45:82-90.

Wang, C., Liu, W., Li, Q., Ma, D., Lu, H., Feng, W., et al. 2014a. Effects of different irrigation and nitrogen regimes on root growth and its correlation with above-ground plant parts in highyielding wheat under field conditions. Field Crops Research 165:138-149.

Wang, Q.J., Lu, C.Y., Li, H.W., He, J., Khokan, K.S., Rabi, G.R., et al. 2014b. The effects of no-tillage with subsoiling on soil properties and maize yield: 12-Year experiment on alkaline soils of Northeast China. Soil and Tillage Research 137:43-49.

Wang, Y., Zhang, X., Liu, X., Zhang, X., Shao, L., Sun, H., et al. 2013. The effects of nitrogen supply and water regime on instantaneous WUE, time-integrated WUE and carbon isotope discrimination in wheat. Field Crops Research 144:236-244.

Xue, Q., Zhu, Z., Musick, J.T., Stewart, B.A., and Dusek, D.A. 2006. Physiological mechanisms contributing to the increased water-use efficiency in wheat under deficit irrigation. Journal of Plant Physiology 163:154-164.

Ye, Y., Wang, G., Huang, Y., Zhu, Y., Meng, Q., Chen, X., et al. 2011. Understanding physiological processes associated with yield-trait relationships in modern wheat varieties. Field Crops Research 124:316-322.
Yousfi, S., Serret, M.D., Márquez, A.J., Voltas, J., and Araus, J.L. 2012. Combined use of $\delta^{13} \mathrm{C}, \delta^{18} \mathrm{O}$ and $\delta^{15} \mathrm{~N}$ tracks nitrogen metabolism and genotypic adaptation of durum wheat to salinity and water deficit. New Phytologist 194:230-244.

Yu, L.P., Huang, G.H., Liu, H.J., Wang, X.P., and Wang, M.Q. 2010. Effects so sprinkler irrigation amount on wheat growth, water consumption, and water use efficiency. Chinese Journal of Applied Ecology 21:2031-2037 (in Chinese).

Zadoks, J.C., Chang, T.T., and Konzak, C.F. 1974. A decimal code for the growth stages of cereals. Weed Research 14:415-421.

Zhang, X., Chen, S., Sun, H., Pei, D., and Wang, Y. 2008. Dry matter, harvest index, grain yield and water use efficiency as affected by water supply in wheat. Irrigation Science 27:1-10.

Zhang, X., Chen, S., Sun, H., Shao, L., and Wang, Y. 2011. Changes in evapotranspiration over irrigated wheat and maize in North China Plain over three decades. Agricultural Water Management 98:1097-1104.

Zhao, D., Shen, J., Lang, K., Liu, Q., and Li, Q. 2013. Effects of irrigation and wide-precision planting on water use, radiation interception, and grain yield of wheat in the North China Plain. Agricultural Water Management 118:87-92.

Zwart, S.J., and Bastiaanssen, W.G.M. 2004. Review of measured crop water productivity values for irrigated wheat, rice, cotton and maize. Agricultural Water Management 69:115. 